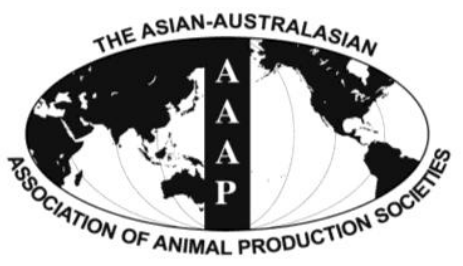

\title{
Knock-in of Enhanced Green Fluorescent Protein or/and Human Fibroblast Growth Factor 2 Gene into $\beta$-Casein Gene Locus in the Porcine Fibroblasts to Produce Therapeutic Protein
}

\author{
Sang Mi Lee, Ji Woo Kim, Young-Hee Jeong, Se Eun Kim, Yeong Ji Kim, Seung Ju Moon, \\ Ji-Hye Lee ${ }^{1}$, Keun-Jung Kim ${ }^{1}$, Min-Kyu Kim¹, and Man-Jong Kang* \\ Department of Animal Science, College of Agriculture and Life Science, \\ Chonnam National University, Gwangju 500-757, Korea
}

\begin{abstract}
Transgenic animals have become important tools for the production of therapeutic proteins in the domestic animal. Production efficiencies of transgenic animals by conventional methods as microinjection and retrovirus vector methods are low, and the foreign gene expression levels are also low because of their random integration in the host genome. In this study, we investigated the homologous recombination on the porcine $\beta$-casein gene locus using a knock-in vector for the $\beta$-casein gene locus. We developed the knock-in vector on the porcine $\beta$-casein gene locus and isolated knock-in fibroblast for nuclear transfer. The knock-in vector consisted of the neomycin resistance gene (neo) as a positive selectable marker gene, diphtheria toxin- $A$ gene as negative selection marker, and $5^{\prime}$ arm and $3^{\prime}$ arm from the porcine $\beta$-casein gene. The secretion of enhanced green fluorescent protein (EGFP) was more easily detected in the cell culture media than it was by western blot analysis of cell extract of the HC11 mouse mammary epithelial cells transfected with EGFP knock-in vector. These results indicated that a knock-in system using $\beta$-casein gene induced high expression of transgene by the gene regulatory sequence of endogenous $\beta$-casein gene. These fibroblasts may be used to produce transgenic pigs for the production of therapeutic proteins via the mammary glands. (Key Words: Knock-in, Homologous Recombination, Therapeutic Proteins, Porcine $\beta$ casein Gene)
\end{abstract}

\section{INTRODUCTION}

Many transgenic animals are produced by microinjection, retroviral vectors, sperm mediated vectors and nuclear transfer methods (Houdebine, 2000; Robl et al., 2007; Houdebine, 2009). Microinjection is the method of injecting a foreign gene into the pronucleus of a fertilized egg using a micro-manipulator, for the expression of a foreign gene, which is the most widely used method

\footnotetext{
* Corresponding Author: M. J. Kang. Tel: +82-62-530-2113, Fax: +82-62-530-2129, E-mail: mjkang@chonnam.ac.kr

${ }^{1}$ Department of Animal Science and Biotechnology, College of Agriculture and Life Sciences, Chungnam National University, Daejeon 305-764, Korea.

Submitted Mar. 27, 2014; Revised Jun. 6, 2014; Accepted Jun. 24, 2014
}

(Gordon and Ruddle, 1981; Palmiter et al., 1982; Hammer et al., 1985; Clark , 1998; Houdebine, 2000).

Animal cloning by nuclear transfer using somatic cells was first successfully applied in sheep (Wilmut et al., 1997). The production of clone animals by nuclear transfer using somatic cells can be used to produce transgenic animals. In this method, the transgenic vector is introduced into the somatic cells before they are used for nuclear transfer. The fundamental principles of the nuclear transfer method were experimentally verified by the production of a human factor IX transgenic sheep using transfected fetal fibroblasts (Schnieke et al., 1997). The generation of transgenic domestic animals by nuclear transfer using transfected cells provides a number of advantages over the classic DNA microinjection technique. One major advantage of this 
method is that integration and expression of the transgene can be investigated in transfected cells before they are used as a nuclear donor (Wolf et al., 2000). Also, transgenesis by nuclear transfer offers a route for random or targeted genetic modification in domestic animals (Schnieke et al., 1997; Robl et al., 2007; Houdebine, 2009).

The production of therapeutic proteins from transgenic animals is one of the most important and significant successes of animal biotechnology. However, the production efficiency of transgenic animals by conventional methods is only $2 \%-3 \%$ and the level of foreign gene expression is also very low, because the foreign genes are integrated at random sites throughout the host animals' genome (Chan, 1999; Wolf et al., 2000).

To overcome the above problems, gene targeting methods using homologous gene recombination techniques have been developed. Gene targeting is a technique which utilizes homologous recombination between an engineered exogenous DNA fragment and the genome of the donor cells (Clark et al., 2000; Piedrahita, 2000; Denning and Priddle, 2003; Wang and Zhou, 2003). Recombination between identical regions contained within the introduced DNA fragment and the native chromosome will lead to the replacement of a portion of the chromosome with the engineered DNA. There are two methods used in gene targeting; the knock-out and knock-in methods. In knockout gene targeting, recombination occurs within the gene. This results in the insertion of a foreign sequence within the middle of the gene, which disrupts the gene. With its sequence interrupted, the altered gene in most cases will be translated into a nonfunctional protein. In knock-in gene targeting, a specific endogenous gene is removed and an exogenous gene is inserted in the specific endogenous locus. Expression of the inserted exogenous gene is then controlled by the gene regulatory sequence of the endogenous gene (Clark et al., 2000; Piedrahita, 2000; Denning and Priddle, 2003; Wang and Zhou, 2003). Genetargeted sheep created by nuclear transfer were generated using ovine fetal fibroblasts which targeted the $\alpha 1$-antitryps gene into the $\alpha 1(\mathrm{I})$ procollagen locus for mammary gland specific expression (McCreath et al., 2000). Using this method, they reported that transgenic sheep were hormonally induced to lactate, and had a high expression $(650 \mu \mathrm{g} / \mathrm{mL})$ of $\alpha 1$-antitryps in their milk. These results indicate that gene targeting is a powerful method to produce animal bioreactors.

When the $\beta$-casein gene was knocked-out by gene targeting in a mouse, the knock-out mouse survived normally and could even become pregnant and nurse its young (Kumar et al., 1994). This result indicates that when the $\beta$-casein gene is knocked-out by gene targeting and a specific foreign gene is inserted in its place, the foreign gene can be expressed by the $\beta$-casein gene regulatory sequence. However, the application of gene targeting to the porcine $\beta$-casein gene locus for the production of bioactive substances in porcine milk has not yet been reported.

Therefore, the aim of this study was to develop a knockin gene targeting system, using the $\beta$-casein gene of porcine to produce bioactive substances.

\section{MATERIALS AND METHODS}

\section{Construction of knock-in vector for expression of enhanced green fluorescent protein or human fibroblast growth factor 2}

Porcine $\beta$-casein genome DNA was cloned previously by our group (Lee et al., 2012). The $\beta$-casein genome DNA was used as a template for the construction of the knock-in vector in this study. The $5.1 \mathrm{~kb} \mathrm{5'}$ arm fragment of porcine $\beta$-casein gene was cloned by polymerase chain reaction (PCR) amplification using a forward primer with an additional NotI site (GCGGCCGCGATATCTAGGGTCT CTTCTAGT) and a reverse primer with an additional NcoI site (CCATGGCGATCAAGTCCTGTGAATGGGGAA). To cloned the 3 'arm of porcine $\beta$-casein gene, genome DNA containing exon 2 to exon 9 was digested by PstI and XbaI restriction enzyme, and then the $2.6 \mathrm{~kb}$ PstI/XbaI fragment was subcloned into the PstI-XbaI site of pBluscript $\mathrm{SK}+(\mathrm{pBSK}+)$ vector to produce the pBSKPstI/XbaI 3'arm plasmid. The pBSK- PstI/XbaI 3'arm plasmid was digested with PstI and XbaI enzyme, bluntended with Klenow, and ligated to SalI and XhoI linker (Takara Co., Shiga, Japan). SalI/XhoI fragments were ligated into the SalI-XhoI site in the pBluscript SK- (pBSK) to produce the pBKS-SalI/XhoI 3'arm plasmid. Human fibroblast growth factor 2 (FGF2) cDNA was cloned by the real-time-PCR, using a forward primer with an additional NcoI site (CCATGGCAGCCGGGAGCATCAC) and a reverse primer with an additional SalI site (GTCGACCCATTAAAATCAGCTC), from cDNA of human hepatocellular liver carcinoma cell line (HepG2) cell. Also, EGFP gene was cloned by PCR, using the pEGFP-N3 vector (Clontech Co., Palo Alto, CA, USA) as a template, using a forward primer with an additional NcoI site (CCATGGTGAGCAAGGGCGAGGA) and a reverse primer with an additional SalI site (GTCGACCGGCCGCT TTACTTGT) primer. SV40 polyA signal $(0.2 \mathrm{~kb})$ was cloned by PCR, using pCMV-Tag1 vector (Stratagene Co., La Jolla, CA, USA) as template, using a forward primer with an additional XhoI site (CTCGAGACTCGA TCGCCCTT) and a reverse primer with an additional EcoRV site (GATATCAATTTACGCGTTAA) primer. The nuclear localization signal (NLS) sequence was cloned by PCR, using pEGFP-N3 vector (Clontech, USA) as a 
template, using sense (GCGGCCGCGATTCG GATTCG GAGTTA) and antisense (ACTAGTCCAGCTGT GGAATG) primers. To the cloned $P G K$-neo gene, pKJ2 neo cassette plasmid (Gibco BRL, Grand Island, NY, USA) was digested with EcoRI and BamHI enzyme, blunt-ended with Klenow, and ligated to EcoRV and SalI linker (Takara Co., Japan). EcoRV/SalI fragments were ligated into the EcoRVSalII site in the pBSK- to produce the pBKS-PGKneo plasmid. All PCR amplified fragments were subcloned into the pGEM T-easy vector (Promega Co., Madison, WI, USA) and the sequence was conformed. Knock-in vectors were constructed as follows: NotI/NcoI $5.1 \mathrm{~kb}$ fragment and NcoI/SalI hman FGF2 or EGFP fragments were inserted into the NotI-SalI site of pBSK+ by 3 fragment ligation to produce pBSK-5' arm-hFGF2 or EGFP plasmid. T-easy NLS plasmid was digested with SpeI enzyme, blunt-ended with Klenow, and digested with NotI. NotI/blunt NLS fragment was ligated into the NotI-EcoRV site of pBSK-5, arm-hFGF2 or EGFP plasmid to produce pBSK-NLS-5, arm-hFGF2 or EGFP plasmid. SV40 polyA fragment (XhoI-EcoRV) and NLS-5' arm- hFGF2 or EGFP fragment
(NotI-SalI) were ligated into the NotI-EcoRV site of pBSK+ by 3 fragment ligation to produce pBSK-NLS-5, armhFGF2 or EGFP-polyA plasmid. PGK-neo fragment (EcoRV-SalI) and 3'arm fragment (SalI-XhoI) were subcloned into the EcoRV-XhoI site of pBSK+ by 3 fragment ligation to produce $\mathrm{pBSK}-\mathrm{PGKneo-3}$ 'arm plasmid. PGKneo-3'arm fragment (EcoRV-XhoI) was inserted into EcoRV-XhoI site of pBSK-NLS-5' arm-hFGF2 or EGFPpolyA plasmid to produce pBSK-NLS-5, arm-hFGF2 or EGFP-polyA-neo-3' arm plasmid. Finally, to produce the knock-in vector, NotI-XhoI fragments of pBSK-NLS-5' arm-hFGF2 or EGFP-polyA-neo-3' arm plasmid were ligated into the NotI-XhoI site in the pMCDT-A plasmid (Gibco BRL, USA). These knock-in vectors consisted of NLS sequence, porcine $\beta$-casein 5 ' arm $(5.1 \mathrm{~kb})$, human FGF2 or EGFP cDNA, SV40 polyA, neomycin resistance gene (neo) as a positive selectable marker gene, porcine $\beta$ casein 3'arm $(2.6 \mathrm{~kb})$, and the diphtheria toxin A fragment $(D T-A)$ gene as a negative selectable marker gene (Figure 1A). We named these knock-in vectors EGFP or hFGF2 knock-in vectors for expression of EGFP or hFGF2 on the

\section{A)}

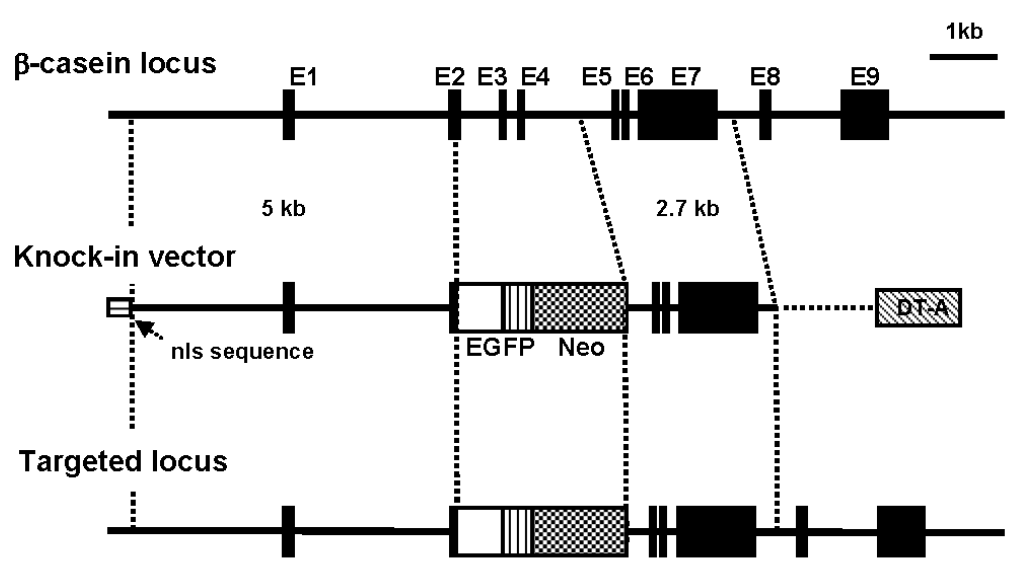

B)

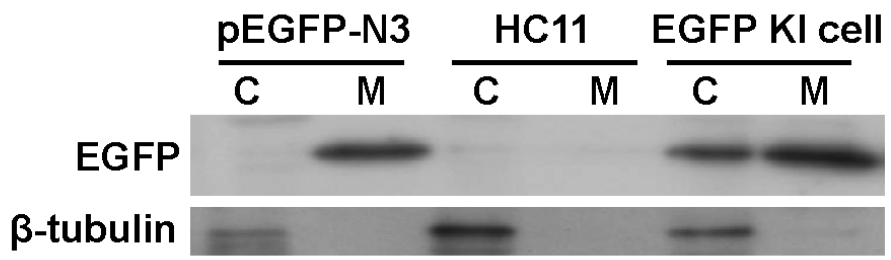

Figure 1. The knock-in strategy in the porcine $\beta$-casein gene locus. (A) Diagram indicating homologous recombination of knock-in vector at the porcine $\beta$-casein gene locus. Solid black box indicates exon of porcine $\beta$-casein gene. Open box, vertical line box, and dotted box indicates cDNA of EGFP or $h F G F 2$ gene, poly A signal sequence and PGK-neo gene without polyA signal sequence, respectively. The PCR primer pairs used for detecting homologous recombinations are shown as primer A, located in the Neo gene, and primer B, located in the out site from the homologous 3' arm. (B) Secretion of EGFP protein in the cell culture media of the HC11 cell transfected with EGFP knock-in vector. C indicated total protein from $\mathrm{HC} 11$ cells as a negative control, pEGFP-N3 cells as a positive control, and EGFP knock-in cells. M indicates protein isolated from media of each cells. The $\beta$-tubulin antibody was used to distinguish between cell and media protein. EGFP, enhanced green fluorescent protein; hFGF2, human fibroblast growth factor 2; PGK, phosphoglycerate kinase promoter; PCR, polymerase chain reaction; HC11, mouse mammary epithelial cell line; pEGFP-N3, plasmid vector enhanced green fluorescent protein-N3. 
porcine $\beta$-asein locus, respectively. For transfection of linearized knock-in vectors to porcine fibroblasts, knock-in vectors were digested with NotI enzyme.

Cell culture of HC11 cell, Transfection and lactogenic hormone induced differentiation

The HC11 cell was cultured in RPMI1640 (HyClone Co., Logan, UT, USA) containing $10 \%$ fetal bovine serum (HyClone Co., USA), 100 unit/mL penicillin and 100 $\mu \mathrm{g} / \mathrm{mL}$ streptomycin (HyClone Co., USA). Transfection of knock-in vector was performed as follows. The HC11 cells were inoculated on $35 \mathrm{~mm}$ dishes at a density of $2.4 \times 10^{5}$ cells/dish, and culture medium was replaced with $1.8 \mathrm{~mL}$ of fresh medium the next day. The cells were then transfected using a jetPEI transfection reagent (Polyplus-transfection, Illkirch, France) according to the manufacturer's instruction using $4 \mu \mathrm{g}$ of Knock-in vector and pEGFP-N3 vector (Clontech Co., USA) as a control. After $24 \mathrm{~h}$, selection was performed for 10 days using $300 \mu \mathrm{g} / \mathrm{mL}$ of G418 (Gibco BRL, USA). For lactogenic hormone induction, the HC11 cells as a negative control and HC11-EGFP cells were cultured in growth media (RPMI1640 [HyClone Co., USA] containing 10\% FBS [HyClone Co., USA], 100 unit/mL penicillin, $100 \mu \mathrm{g} / \mathrm{mL}$ streptomycin, $5 \mu \mathrm{g} / \mathrm{mL}$ insulin [Sigma Chemical Co., St Louis, MO, USA] and $10 \mu \mathrm{g} / \mathrm{mL}$ epidermal growth factor [Invitrogen Co., Carlsbad, CA USA]). The lactogenic hormone induction of HC11 cells was described previously (Doppler et al., 1989). Briefly, cells were grown to confluence and were maintained for 3 days in growth media. The growth media was removed and washed with PBS three times to remove the remaining serum. The cells were then cultured with induction media (RPMI1640 [HyClone Co., USA] containing 100 unit/mL penicillin, $100 \mu \mathrm{g} / \mathrm{mL}$ streptomycin, $5 \mu \mathrm{g} / \mathrm{mL}$ insulin [Sigma Chemical Co., USA], $1 \mu \mathrm{M}$ DEX [Sigma Chemical Co., USA], $5 \mu \mathrm{g} / \mathrm{mL}$ prolactin [Sigma Chemical Co., USA] and $10 \%$ FBS [HyClone Co., USA]) during 3 days without changing the medium.

\section{Culture of porcine ear fibroblasts and transfection}

Porcine ear fibroblasts were prepared from ear tissues of three-way crossbreds (LWD) obtained at the slaughterhouse, according to a previously reported method (Ahn et al., 2011). The cells were cultured with growth medium (DMEM, 15\% FBS, 1×non-essential amino acids, $1 \times$ sodium pyruvate, $10^{-4} \mathrm{M} \beta$-mercaptoethanol, $100 \mathrm{unit} / \mathrm{mL}$ penicillin, $100 \mu \mathrm{g} / \mathrm{mL}$ streptomycin) for electroporation. The transfection was conducted according to a previously reported method (Kim et al., 2012), as follows. The cells were trypsinized and resuspended at a concentration of $1.25 \times 10^{7}$ cells $/ \mathrm{mL}$ in F10 nutrient mixture. The cell suspension $(400 \mu \mathrm{L})$ was electroporated in a $4 \mathrm{~mm}$ cuvette using $10 \mu \mathrm{g}$ knock-in vectors with four- $1 \mathrm{~ms}$ pulses using
$400 \mathrm{~V}$ capacitive discharges by a BTX Electro-cell manipulator (ECM 2001, BTX, Holliston, MA, USA). After electroporation, the cuvette was placed on ice for $10 \mathrm{~min}$. The cells in the cuvette were resuspended in $10 \mathrm{~mL}$ of medium, distributed into a 48-well plate, and further cultured. After $24 \mathrm{~h}$, selection was performed for 11 days using $300 \mu \mathrm{g} / \mathrm{mL}$ of G418 (Gibco BRL, Grand Island, NY, USA). After selection, the single colonies were passaged into 24-well plates, and were further cultured for the analysis of positive colonies.

\section{Preparation of protein and Western blot analysis}

Protein from culture media was isolated by acetone precipitation as follows. Cultured medium from lactogenic hormone induced cells was collected in a $15 \mathrm{~mL}$ tube and was centrifuged at $800 \mathrm{rpm}, 4^{\circ} \mathrm{C}$ for $5 \mathrm{~min}$ to remove floating matter. Four volumes of acetone (Merck Co., Darmstadt, Germany) was added in the collected medium and was maintained at $-20^{\circ} \mathrm{C}$ overnight. The collected medium was then centrifuged at $13,000 \mathrm{rpm}, 4^{\circ} \mathrm{C}$ for 30 min. After centrifugation, the protein pellet was dissolved in $100 \mu \mathrm{L}$ of sodium chloride-tris-EDAT (TEN) buffer (40 $\mathrm{mM}$ Tris $\mathrm{HCl}$ [pH 7.4], $1 \mathrm{mM}$ cobalt ethylenediaminetetraacetate [EDTA], $150 \mathrm{Mm} \mathrm{NaCl}, 0.05 \%$ Triton X-100) containing inhibitor cocktail and phenylmethylsulfonyl fluoride (PMSF). Protein from cells was prepared by TEN buffer (40 mM Tris $\mathrm{HCl}$ [pH 7.4], $1 \mathrm{mM}$ EDTA, $150 \mathrm{Mm}$ $\mathrm{NaCl}, 0.05 \%$ Triton $\mathrm{X}-100]$ containing inhibitor cocktail and PMSF in cells. The protein concentration was measured using a Bio-Rad protein assay kit as per the manufacture's instructions.

For western blots, equivalent amounts of protein $(50 \mu \mathrm{g})$ were separated by SDS-polyacrylamide gel electrophoresis (SDS-PAGE) $(10 \%$ gel) and were transferred to polyvinylidene fluoride (PVDF) membranes (Bio-Rad Co., Hercules, CA, USA). The membranes were blocked in 5\% skim milk in tris buffered saline with tween 20 (TBST) for $2 \mathrm{~h}$ at room temperature. The membrane was subsequently incubated for $2 \mathrm{~h}$ at room temperature with monoclonal anti-green fluorescent protein (1:2,000 dilution; Ab Frontier, Seoul, Korea) in TBST solution containing $0.1 \%$ bovine serum albumin (BSA, Sigma Chemical Co., USA). After three times washing with TBST, the membranes were then incubated for $2 \mathrm{~h}$ at room temperature with horseradish peroxidase-conjugated goat anti-rabbit immunoglobulin $\mathrm{G}$ (1:2,000 dilution; SantaCruz Co., Santa Cruz, CA, USA) in TBST containing $0.1 \%$ BSA (Sigma Chemical Co., USA). The protein bands were visualized by incubation with enhanced chemiluminescence (Amersham Co., Arlington Heights, IL, USA).

\section{Polymerase chain reaction analysis of knock-in colony Preparation of genome DNA from G418-resistant}


colonies was performed according to a previously reported method (Kim et al., 2012). When the cells were subcultured from 24 -well plates to 12 -well plates, $200 \mu \mathrm{L}$ of cell suspension from the 24 -well plates were recovered by centrifugation and suspension with $40 \mu \mathrm{L}$ of deionized water containing $0.05 \mathrm{mg} / \mathrm{mL}$ proteinase $\mathrm{K}$ (Roche, Foster City, CA, USA). These cells were incubated at $55^{\circ} \mathrm{C}$ for $130 \mathrm{~min}$ and were then heated to $98^{\circ} \mathrm{C}$ for $10 \mathrm{~min}$ in order to inactive the proteinase $\mathrm{K}$.

The 1st PCR was performed with $20 \mu \mathrm{L}$ genome extract, neo sense (GCCTGCTTGCCGAATATCATGGTGGAAA $\mathrm{AT}$ ) and 3 ' $\beta \mathrm{C}$ antisense (GGCATGTGGGGAAATA ATTGCACATAAGGA) primers, $1 \times$ PCR buffer, $0.5 \mathrm{U}$ Ex Taq polymerase (Takara Co., Japan) and $200 \mu \mathrm{M}$ of dNTP mixture as follows; predenaturation at $94^{\circ} \mathrm{C}$ for $2 \mathrm{~min}$, denaturation at $94^{\circ} \mathrm{C}$ for $30 \mathrm{~s}$, annealing at $66^{\circ} \mathrm{C}$ for $30 \mathrm{~s}$, and extension at $72^{\circ} \mathrm{C}$ for $5 \mathrm{~min}, 35$ cycles from denaturation to extension, and final extension at $72{ }^{\circ} \mathrm{C}$ for 10 min. The PCR products were confirmed by electrophoresis on $0.8 \%$ agarose gel. As a result, a band of approximately $3.2 \mathrm{~kb}$ was confirmed.

For accurate analysis of knock-in colonies by 2nd PCR, the genome DNA were isolated from the positive cells of the 1st PCR analysis, and 2nd PCR amplification was conducted with the same conditions of the 1st PCR. The PCR products $(20 \mu \mathrm{L})$ were confirmed by electrophoresis on $0.8 \%$ agarose gel.

\section{Southern blot analysis}

Final confirmation of knocked-in cells was performed by southern blot analysis. Ten $\mu \mathrm{g}$ of the genomic DNA was digested with EcoRV (Takara Co., Japan), followed by purification. The DNA was electrophoresed on $0.8 \%$ agarose gel, and was then transferred on nitrocellulose membrane (Bio-Rad Co., USA). The membrane was washed with $2 \times$ saline-sodium citrate (SSC) buffer for $30 \mathrm{~s}$. The DNA was cross-linked onto the membrane by using a UV crosslinker, followed by hybridization in the solution containing $5 \times$ saline-sodium phosphate EDTA (SSPE), $5 \times$ Denhardt's (Sigma Chemical Co., USA), $1 \%$ sodium dodecyl sulfate (SDS) (w/v) and $50 \%$ formamide (w/v) (Sigma Chemical Co., USA) at $42^{\circ} \mathrm{C}$ for $15 \mathrm{~h}$. A probe was prepared by using a $600 \mathrm{bp} / S p e \mathrm{I}-E c o R I$ DNA fragment containing the porcine $\beta$-casein exon 9, random labeling kit (Amersharm, Amersharm, England) and ( $\alpha-32 \mathrm{P}) \mathrm{dCTP}(110$ $\mathrm{TBq} / \mathrm{mmol}$, Amersharm., England). A neo probe was also prepared by using $600 \mathrm{bp} / P s t \mathrm{I}$ DNA fragment from $\mathrm{pKJ} 2$ plasmid. The concentration of the probe for hybridization was one million $\mathrm{cpm} / \mathrm{mL}$ hybridization solution. After hybridization, the membrane was washed three times with $0.2 \% \mathrm{SSC}$ and $0.1 \% \mathrm{SDS}(\mathrm{w} / \mathrm{v})$ at $68^{\circ} \mathrm{C}$ for $20 \mathrm{~min}$, exposed on X-ray film (Sigma Chemical Co., St Louis, MO, USA) at $-80^{\circ} \mathrm{C}$ for 4 days, and then developed.

\section{RESULTS}

\section{Construction of knock-in vector for expression enhanced green fluorescent protein or human fibroblast growth factor 2 on the porcine $\beta$-casein locus}

Diagram of knock-in vector for expression of EGFP or hFGF2 on the porcine $\beta$-casein locus was shown in Figure 1A. The knock-in vector was constructed using 5' and 3' homologous arms from $\beta$-casein genomic DNA with human FGF2 or EGFP, polyA signal, positive and negative selection marker. The 5' homologous arm of the knock-in vector was $5 \mathrm{~kb}$ containing a promoter, exon 1 , and intron 1 , and the 3 ' homologous arm was $2.7 \mathrm{~kb}$ containing exons 5 , 6 , and 7. The start codon (ATG) site of exon 2 of porcine $\beta$ casein gene was replaced with ATG of human basic FGF2 or EGFP, which could be secreted protein by the porcine $\beta$ casein promoter. Neo gene was used as a positive selection marker and diphtheria toxin A was used as a negative selection marker. These selection markers did not contained a polyA signal. A NLS was inserted in the 5' region of the knock-in vector to easily enter cells. In this study, the knock-in vector was designed using a positive-negative selection marker and a poly A trap strategy. Homologous recombination depending on the knock-in vector is shown in Figure 1A.

\section{Expression of porcine $\beta$-casein knock-in vector in mouse mammary gland $\mathrm{HC} 11$ cells}

Because, knock-in vectors constructed in this study contained about $3 \mathrm{~kb}$ of porcine $\beta$-casein promoter and were designed for the insertion of ATG of EGFP or hFGF2 instead of ATG of porcine $\beta$-casein gene, we analyzed the expression of EGFP protein by western blot using protein isolated from cells and media of HC11 mouse mammary epithelial cell transfected EGFP knock-in vector. The EGFP expression was detected in the cells and media of cells transfected with the EGFP knock-in vector. However, EGFP protein was more expressed into the media than HC11 cells (Figure 1B).

\section{Efficiency of gene targeting in porcine somatic cells}

Primary porcine ear fibroblasts were used for electroporation with the knock-in vector. G418-resistent colonies were screened by 3' PCR (1st PCR) with neo sense (primer A, a sequence from the 3' end of neo gene) and porcine $\beta$-casein anti-sense (primer $\mathrm{B}$, a sequence from the intron 7 in sequence located outside the 3 ' recombination arm) primers (Figure 1A). Thus, only through successful targeting of the porcine $\beta$-casein locus would the expected $3.0 \mathrm{~kb}$ PCR products be obtained. The PCR analysis was performed using 387 colonies in the fibroblasts transfected FGF knock-in vector. Also, 405 G418 resistant colonies were analyzed by PCR in the fibroblasts transfected with 
Table 1. Efficiency of gene targeting at the $\beta$-casein gene locus with knock-in vector for EGFP and human FGF2 expression

\begin{tabular}{lccccc}
\hline $\begin{array}{c}\text { Knock-in } \\
\text { vector }\end{array}$ & Source of cells & $\begin{array}{c}\text { No. of } \\
\text { cells transfected }\end{array}$ & $\begin{array}{c}\text { No. of G418 } \\
\text { analyzed by PCR }\end{array}$ & $\begin{array}{c}\text { No. of PCR positive } \\
\text { colonies }\end{array}$ & $\begin{array}{c}\text { No. of southern blot- } \\
\text { positive colonies }(\%)\end{array}$ \\
\hline hFGF2 & Male & $5 \times 10^{6}$ & 387 & 4 & 2 \\
EGFP & Male & $5 \times 10^{6}$ & 405 & 2 & 1 \\
Total & & $1 \times 10^{7}$ & 792 & 6 & $3(0.38)$ \\
\hline
\end{tabular}

EGFP, enhanced green fluorescent protein; FGF2, fibroblast growth factor 2; PCR, polymerase chain reaction.

the EGFP knock-in vector. As a result, four positive colonies were identified in fibroblasts transfected with the FGF knock-in vector. Finally, two positive colonies were confirmed by southern blot analysis in male ear fibroblasts (Table 1). Moreover, when the EGFP knock-in vector was introduced into ear fibroblasts, only one colony was identified by PCR and southern blot analysis (Table 1).

Figure 2A shows the 3' PCR results for a representative group of G418-colonies. In the fibroblast transfected FGF knock-in vector, the G2 colony showed a strong band (upper panel). Therefore, two colonies (F3 and F5) showed a strong band and other colonies (F1, F7, and F8) presented a week band in the fibroblast transfected FGF knock-in vector (Figure 2A lower panel). Therefore, to further confirm successful targeting at the porcine $\beta$-casein locus, we carried out southern blot analysis using porcine $\beta$-casein exon 9 and neo probe in the FGF knock-in fibroblast. As a result of southern blot analysis, a mutant allele was identified in F3 and F5 colonies (Figure 2B). When the Exon9 - probe was used, $11.5 \mathrm{~kb}$ of wild type allele and 6.1 kbp of mutant allele were identified in FGF Knock-in fibroblasts (Figure 2B upper). Also, $6.1 \mathrm{~kb}$ of mutant allele was identified in the same Knock-in fibroblasts (Figure 2B under) hybridized with neo-probe. The efficiency of gene targeting at the porcine $\beta$-casein locus was $0.38 \%$.

\section{DISCUSSION}

In this study, knock-in vectors were constructed to express human FGF2 and EGFP using the porcine $\beta$-casein gene. Expression of EGFP in the knock-in vector was analyzed in the mouse mammary gland cell line, HC 11

\section{A) PCR analysis}

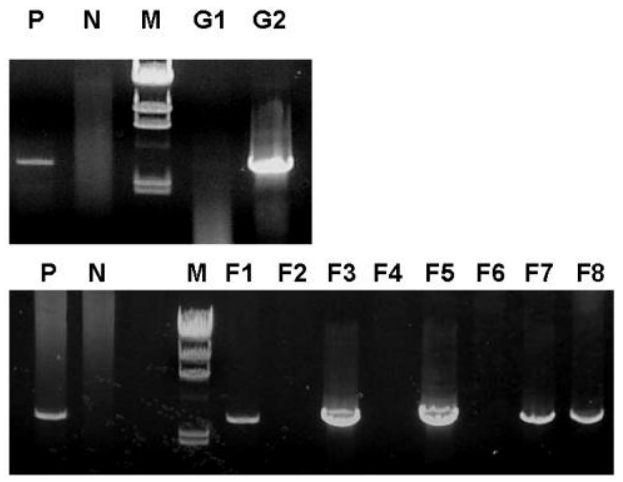

\section{B) Southern blot analysis}

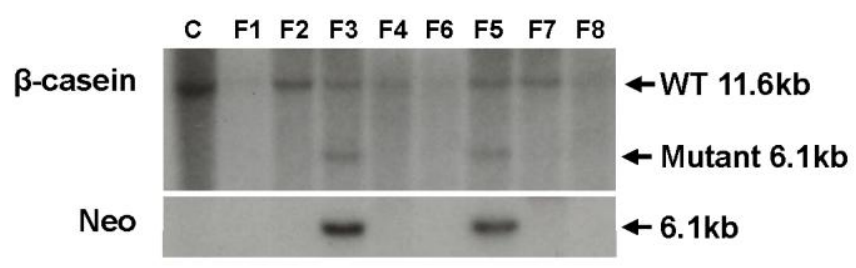

Figure 2. Analysis of knock-in fibroblasts by PCR and southern blot analysis. (A) Representative EtBr stained agarose gel of PCR amplicons from primer A and B of G418-resistant colonies, selected from a transfection with linear knock-in vector. M, size marker ( $\gamma /$ HindIII); N, negative control; P, positive control; Number, G418-resistant colonies. The upper panel indicates the analysis of EGFP knock-in fibroblasts and the lower panel indicates the analysis of hFGF2 knock-in fibroblasts. (B) Analysis of hFGF2 knock-in fibroblasts by southern blot. The wild type allele was detected with a $11.6 \mathrm{~kb}$ band and mutant alleles, depending on the homologous recombination, which was detected with a $6.1 \mathrm{~kb}$ band. Control hybridization with Neo probe is only detected in the knock-in fibroblasts. PCR, polymerase chain reaction; EtBr, ethidium bromide; EGFP, enhanced green fluorescent protein; hFGF2, human fibroblast growth factor 2 . 
cells. Also, we successfully isolated knock-in fibroblast for nuclear transfer.

Previously, it was reported that the expression of transgenes in transgenic animals was dependent on the insertion site of the transgene, structure of the expression vector, and other related factors (Houdebine et al., 2000). In previous studies, knock-in mice that targeted replacement of the mouse apolipoprtein $\mathrm{E}$ gene with the human apolipoprotein E (human APOE) allele were produced, and the human $A P O E$ gene was expressed under the natural regulation of this protein by the gene regulatory sequence of the mouse APOE gene (Sullivan et al., 1997; Sullivan et al., 1998; Hamanaka et al., 2000). In addition, it has been reported that the exogenous $h t P A m$ gene was targeted to the $\beta$-casein locus in a goat somatic cell using a knock-in system (Shen et al., 2007).

Therefore, we examined whether knock-in vector containing the porcine $\beta$-casein gene could be used to target the porcine $\beta$-casein locus for the stable expression of EGFP or hFGF2 using the gene regulation sequence of the porcine $\beta$-casein locus. In this experiment, the knock-in vector was constructed using the porcine $\beta$-casein genome locus, neo gene as the positive selection marker and diphtheria toxin A as the negative selection marker. G418 was then used to select the somatic cells in which homologous recombination with the target vector occurred, since only the cells containing the target vector can survive under these conditions due to the expression of the negative marker, diphtheria toxin A. A gene targeting vector that contained the neo gene as a positive selection marker and diphtheria toxin $\mathrm{A}$ as a negative selection marker was previously used in mouse gene targeting with a mouse embryonic stem cell line (Yanagawa et al., 1999). Therefore, the knock-in vector constructed in this study may function normally in porcine somatic cells.

The EGFP expression was observed in the mouse mammary gland HC11 cells that had been transfected with the knock-in vector. Also, EGFP protein was secreted into the cell culture media more than the cell. The EGFP was under the control of the $3 \mathrm{~kb}$ promoter in the 5 ' arm of the knock-in vector, since the promoter in the 5' arm of the knock-in vector may have basic transcriptional components. These results indicated that the expression of EGFP gene was regulated by the gene regulatory sequence of porcine $\beta$ casein gene in the mammary gland epithelial cells. A similar result was reported for green fluorescent protein (GFP) expression in somatic cells transfected with knock-in vector, where the cells containing the knock-in vector stably expressed GFP (Shen et al., 2005). In addition, Shen et al. constructed a knock-in vector containing the human tissue plasminogen activator mutant gene, and somatic cells were successfully transfected with this vector via homologous recombination. They then made cloned embryos using the somatic cells containing this knock-in vector, and GFP expression was observed in the embryo. They used the neo gene as a positive selection marker and thymidine kinase as a negative selection marker. Using gene-targeted cell lines as donor cells for nuclear transfer, a total of 600 reconstructed embryos were obtained, and 146 developed cloned embryos were transferred to 16 recipient goats, three of which became pregnant at day 90 (Shen et al., 2007).

In this study, knock-in somatic cells, which may be used to produce a mammary gland bioreactor, were generated by gene targeting to the $\beta$-casein gene locus using a human FGF and EGFP knock-in vector. Previously, knock-in somatic cells were introduced into goat to produce recombinant protein from mammary glands (Shen et al., 2004). An efficient strategy to promote homologous recombination is required to target specific genes in the somatic cells of domestic animals. The targeting frequency in somatic cells varied from $9 \times 10^{-5}$ cell to $1.6 \times 10^{-7}$ per electroporated cells (Denning and Priddle, 2003). Several knock-in modifications have been reported in goat using the $\beta$-casein gene locus and somatic cells (Shen et al., 2004; Shen et al., 2005; Li et al., 2006; Shen et al., 2007). In this study, we isolated 3 colonies from 875 G418 resistance colonies. The targeting efficiency was $5 \times 10^{-6}$ per electroporated cells. These results indicated that this knockin system can be used for the development of knock-in cells for the expression of interesting genes on the $\beta$-casein gene locus. In the study, two of five colonies in the FGF knock-in fibroblast were detected by southern blot analysis. Three PCR positive colonies were not detected by southern blot analysis. We thought that these results indicated that some PCR-positive signal may come from PCR artifacts. However, these southern results strongly indicated that knock-in fibroblast had insertions of targeting vectors on the porcine $\beta$-casein gene locus.

\section{CONCLUSION}

These experiments indicate that a human FGF2 and EGFP expressing knock-in vector was constructed and transfected into mouse mammary gland $\mathrm{HC} 11$ cells. Thus, the expression of FGF2 and EGFP in mammary glands can potentially be accomplished using HC11 cells. Also, we isolated knock-in cells that introduced these knock-in vectors. These results indicated that knock-in cells were established for efficient and reproducible gene targeting in porcine ear fibroblasts by inserting the exogenous human FGF and EGFP cDNA into the $\beta$-casein gene locus. Knockin cells may be used in the production of transgenic porcine that expressed EGFP or hFGF2 on the porcine $\beta$-casein gene locus.

\section{ACKNOWLEDGMENTS}

This work was supported by a grant from the Next- 
Generation BioGreen 21 Program (No. PJ009591), Rural Development Administration, Republic of Korea.

\section{REFERENCES}

Ahn, K. S., Y. J. Kim, M. Kim, B. H. Lee, S. Y. Heo, M. J. Kang, Y. K. Kang, J. W. Lee, K. K. Lee, J. H. Kim, W. G. Nho, S. S. Hwang, J. S. Woo, J. K. Park, S. B. Park, and H. Shim. 2011. Resurrection of an alpha-1,3-galactosyltransferase genetargeted miniature pig by recloning using postmortem ear skin fibroblast. Theriogenology 75:933-939.

Chan, A. W. S. 1999. Transgenic animals: Current and alternative strategies. Cloning. 1:25-46.

Clark, A. J. 1998. The mammary gland as a bioreactor: expression, processing, and production of recombinant proteins. J. Mammary Gland Biol. Neoplasia 3:337-350.

Clark, A. J., S. Burl, C. Denning, and P. Dickinson. 2000. Gene targeting in livestock: A preview. Transgenic Res. 9:263-275.

Denning, C. and H. Priddle. 2003. New frontiers in gene targeting and cloning: success, application and challenges in domestic animals and human embryonic stem cells. Reproduction 126:111.

Doppler, W., B. Groner, and R. K. Ball. 1989. Prolactin and glucocorticoid hormones synergistically induce expression of transfected rat $\beta$-casein gene promoter constructs in a mammary epithelial cell line. Proc. Nat. Acad. Sci. USA. 86:104-108.

Gordon, J. W. and F. H. Ruddle. 1981. Integration and stable germ line transmission of genes injected into mouse pronuclei. Science 214:1244-1246.

Hamanaka, H., Y. Katoh-Fukui, K. Suzuki, M. Kobayashi, R. Suzuki, Y. Motegi, Y. Nakahara, A. Takeshita, M. Kawai, K. Ishiguro, M. Yokoyama, and S. C. Fujita. 2000. Altered cholesterol metabolism in human apolipoprotein $\mathrm{E}_{4}$ knock-in mice. Hum. Mol. Genet. 9:353-361.

Hammer, R. E., V. G. Pursel, C. E. Rexroad, R. J. Wall, D. J. Bolt, K. M. Ebert, R. D. Palmiter, and R. L. Brinster. 1985. Production of transgenic rabbits, sheep and pigs by microinjection. Nature 315:680-683.

Houdebine, L. M. 2000. Transgenic animal bioreactors. Transgenic Res. 9:305-320.

Houdebine, L. M. 2009. Production of pharmaceutical proteins by transgenic animals. Comp. Immunol. Microbiol. Infect. Dis. 32:107-121.

Kim, J. W., H. M. Kim, S. M. Lee, and M. J. Kang. 2012. Porcine knock-in fibroblasts expressing hDAF on $\alpha-1,3-$ galactosyltransferase (GGTA1) gene locus. Asian Australas. J. Anim. Sci. 25:1473-1480.

Kumar, S., A. R. Clarke, M. L. Hooper, D. S. Horne, H. A. J. Law, J. Leaver, A. Springbett, E. Stevenson, and P. Simons. 1994. Milk composition and lactation of $\beta$-casein-deficient mice. Proc. Natl. Acad. Sci. USA. 91:6138-6142.

Lee, S. M., H. M. Kim, S. J. Moon, and M. J. Kang. 2012. Cloning and molecular characterization of porcine $\beta$-casein gene (CNS2). Asian Australas. J. Anim. Sci. 25:421-427.

Li, L., W. Shen, Q. Y. Pan, L. J. Min, Y. J. Sun, Y. W. Fang, J. X. Deng, and Q. J. Pan. 2006. Nuclear transfer of goat somatic cells transgenic for human lactoferrin. Yi. Chuan. 28:1513-
1519.

McCreath, K. J., J. Howcroft, K. H. Campbell, A. Colman, A. E. Schnieke, and A. J. Kind. 2000. Production of gene-targeted sheep by nuclear transfer from cultured somatic cells. Nature 405:1066-1069.

Palmiter, R. D., P. L. Brinster, R. E. Hammer, M. E. Trumbauer, M. G. Rosenfeld, N. C. Birnberg, and R. M. Evans. 1982. Dramatic growth of mice that develop from eggs microinjected with metallothionein-growth hormone fusion genes. Nature 300:611-615.

Piedrahita, J. A. 2000. Targeted modification of the domestic animal genome. Theriogenology 53:105-116.

Robl, J. M., Z. Wang, P. Kasinathan, and Y Kuroiwa. 2007. Transgenic animal production and animal biotechnology. Theriogenology 67:127-133.

Schnieke, A. E., A. J. Kind, W. A. Ritchie, K. Mycock, A. R. Scott, M. Ritchie, I. Wilmut, A. Colman, and K. H. Campbell. 1997. Human factor IX transgenic sheep produced by transfer of nuclei from transfected fetal fibroblasts. Science 278:21302133.

Shen, W., Z. T. Yang, L. Y. Tian, X. J. Wu, H. Chen, P. T. Huang, and J. X. Deng. 2004. The ht-PAm cDNA knock-in the goat beta-casein gene locus. Sheng. Wu. Gong. Cheng. Xue. Bao. 20:361-365.

Shen, W., L. J. Min, L. Li, Q. J. Pan, X. J. Wu, Y. R. Zhou, and J. X. Deng. 2005. High-efficient gene targeting of goat mammary epithelium cell by the multi-selection mechanism. Yi. Chuan. Xue. Bao. 32:366-371.

Shen, W., G. Lan, X. Yang, L. Li, L. Min, Z. Yang, L. Tian, X. Wu, Y. Sun, H. Chen, J. Tan, J. Deng, and Q. Pan. 2007. Targeting the exogenous htPAm gene on goat somatic cell beta-casein locus for transgenic goat production. Mol. Reprod. Dev. 74:428-434.

Sullivan, P. M., H. Mezdour, Y. Aratani, C. Knouff, J. Najib, R. L. Reddicki, S. H. Quarfordt, and N. Maeda. 1997. Targeted replacement of the mouse apolipoprotein $\mathrm{E}$ gene with the common human APOE3 allele enhances diet-induced hypercholesterolemia and atherosclerosis. J. Biol. Chem. 272:17972-17980.

Sullivan, P. M., H. Mezdour, S. H. Quarfordt, and N Maeda.1998. Type III hyperlipoproteinemia and spontaneous atherosclerosis in mice resulting from gene replacement of mouse apoe with human APOE 2. J. Clin. Invest. 102:130-135.

Wang, B. and J. Zhou. 2003. Specific genetic modifications of domestic animals by gene targeting and animal cloning. Reprod. Biol. Endocrinol. 1:103.

Wilmut, I., A. E. Schnieke, J. McWhir, A. J. Kind, and K. H. S. Campbell. 1997. Viable offspring derived from fetal and adult mammalian cells. Nature 385:810-813

Wolf, E., W. Schernthaner, V. Zakhartchenko, K. Prelle, M. Stojkovic, and G. Brem. 2000. Transgenic technology in farm animals - progress and perspectives. Exp. Physiol. 85:615-625.

Yanagawa, Y., T. Kobayashi, M. Ohnishi, T. Kobayashi, S. Tamura, T. Tsuzuki, M. Sanbo, T. Yagi, F. Tashiro, and J. I. Miyazaki. 1999. Enrichment and efficient screening of ES cells containing a targeted mutation: The use of DT-A gene with the polyadenylation signal as a negative selection maker. Transgenic Res. 8:215-221. 